
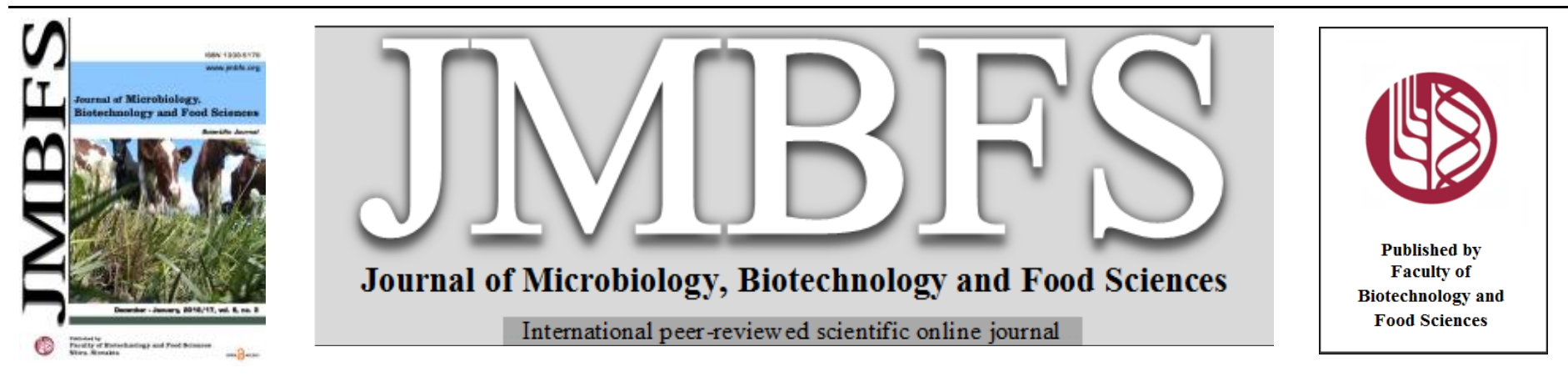

\title{
GLUCOSE CONSUMPTION AND LACTIC ACID FORMATION IN MILLET SOURDOUGH FERMENTED WITH DIFFERENT STRAINS OF LACTIC ACID BACTERIA
}

\author{
Renata Choińska* ${ }^{l}$, Hanna Giryn ${ }^{l}$, Katarzyna Piasecka-Jóźwiak ${ }^{1}$, Danuta Kotyrba ${ }^{1}$, Elzbieta Bartosiak ${ }^{1}$
}

Address(es): dr rer nat inż. Renata Choińska,

${ }^{1}$ Prof. Wacław Dąbrowski Institute of Agricultural and Food Biotechnology, Rakowiecka 36, 02-532 Warszawa, Poland, +48 226063697.

*Corresponding author: renata.choinska@ibprs.pl

doi: $10.15414 / j m b f s .2016 / 17.6 .3 .921-923$

\section{ARTICLE INFO}

Received 11.9. 2015

Revised 21.9. 2016

Accepted 5. 10. 2016

Published 1. 12. 2016

Regular article open $\partial$ access

\begin{abstract}
The consumption of glucose and production of lactic acid by selected autochtonous strains of facultatively heterofermentative Lactobacillus coryniformis, Pediococcus pentosaceus and Pediococcus acidilactici species, in millet sourdoughs was studied. Glucose consumption and lactic acid concentration were analyzed after $24 \mathrm{~h}, 48 \mathrm{~h}$ and $96 \mathrm{~h}$ of sourdough incubation. They varied significantly depending on the strain. The highest production of lactic acid in all fermentation steps was found in sourdough fermented with Pediococcus acidilactici strain, whereas the lowest amount of this metabolite was found in sourdoughs fermented with Pediococcus pentosaceus ZFP5. Lactic acid concentration decreased in the successive fermentation steps and after $96 \mathrm{~h}$ of sourdoughs fermentation its level was of about $44 \%$ lower than after $24 \mathrm{~h}$ of incubation. Glucose was completely consumed in all samples after $96 \mathrm{~h}$ of fermentation.
\end{abstract}

Keywords: lactic acid, millet, sourdough, Lactobacillus coryniformis, Pediococcus pentosaceus, Pediococcus acidilactici

\section{INTRODUCTION}

The increasing demand for baked products with a high nutritional value or health benefits is raising the need for the use of alternative (non-wheat) cereals like rice, maize, millet, and sorghum in the baking industry. The alternative cereals have received extensive scientific and technological attention due to better healthpromoting composition, especially regarding minor components present in grains (dietary fiber, resistant starch, minerals, vitamins, phenolic compounds) (Coda et al., 2014). The greatest advantage of the alternative cereals is a lack of gluten, the causative agent for celiac disease (Moroni et al., 2009).

Among the alternative cereals, millet is one of the oldest cultivated plants. In ancient times, it was prevalent in Asia, Africa and central regions of Europe. Millet is unique due to its short growing seasons and its capability of producing good yields of grain under conditions unfavorable to most other cereals. Millet is desirable in man's diet because it is easily digestible and is a rich source of various macroelements including calcium, potassium, magnesium, sodium and valuable unsaturated fatty acids. Moreover, millet contains B vitamins, especially niacin, B6 and folic acid (Verma et al., 2013). In terms of protein content and fat, millet grains outweigh popular oat and buckwheat grains. The energy of millet grains is similar to that of rice, buckwheat, but their nutritional values are higher. Effects of millet proteins are comparable to the biological value of proteins of wheat, maize, and beans. Owing to its valuable nutritional values, millet has received a renewed interest among consumers of the European countries. It can be used in several ways, e.g., it may be ground into flour and made into a host of different non-yeast breads. Millet grains and flour are commonly used for making fermented products. Traditional foods prepared with natural fermentation of millet are: gruels, porridges, soups, and fermented beverages. Millet flour can also be used for sourdough preparation. However, the use of the millet-based sourdough in the baking industry is not well standardized. Millet, like the other alternative cereals, is characterized by a low baking quality and final sensory quality (Gallagher et al., 2004). These disadvantages limit the use of such flour in the bread making process. One of the ways to overcome these problems is the improvement of fermentation technology, with the main challenge being the design of well-defined starter cultures with functional features for sourdough preparation. It has been reported that lactic acid bacteria fermentation of alternative flours has a relevant influence on sensory as well as baking qualities, providing final products with desirable properties (Coda $\boldsymbol{e t}$ al., 2010). The huge benefit of the consumption of the alternative flour-based bakery products on health together with increasing demand for healthier products affords researchers the opportunity to find new microbial biodiversity for food processing. Therefore, an increasing number of studies has been recently observed that address the lactic acid bacteria (LAB) microbiota of alternative cereals. On the basis of these studies, it has been found that the selected autochthonous lactic acid bacteria are one of the best candidates to ferment the sourdough. Sourdough fermentation with such species leads to an increased value of in vitro protein digestibility and to improvement of the nutritional and sensory potential of non-wheat grains (Coda et al., 2011; Sterr et al., 2009). It was also observed that the type of cereals plays an important role in starters selection (Moroni et al., 2010). During the selection of the proper starter cultures, consideration should also been given to the sensory characteristics of final products. Therefore, studies on the biochemical pathways of lactic acid bacteria leading to the formation of flavor compounds and their precursors are necessary. The objective of our study was to evaluate the behavior of the selected facultatively heterofermentative lactic acid bacteria strains i.e.: two different strains of Lactobacillus coryniformis, three strains of Pediococcus pentosaceus and one strain of Pediococcus acidilactici in millet sourdoughs. In particularly, the production of lactic acid by the selected strains was investigated.

\section{MATERIAL AND METHODS}

\section{Microorganisms}

Six lactic acid bacteria strains (LAB), previously isolated form homemade millet sourdoughs, were used in this study: Lactobacillus coryniformis ZFP1 and ZFP4; Pediococcus pentosaceus ZFP2, ZFP3 and ZFP5; Pediococcus acidilactici ZFP6. These strains were identified by $16 \mathrm{~S}$ rDNA sequencing. LAB were grown anaerobically in MRS medium at $30{ }^{\circ} \mathrm{C}$.

\section{Sourdough preparation and fermentation}

Millet flour (Bio Babalscy, Poland) was used for fermentation of sourdoughs. Sourdoughs were prepared by mixing sterile tap water and whole meal flour of millet in a 1:1 (w/w) ratio. The dough yield was 200. The fermentations were carried out at $25{ }^{\circ} \mathrm{C}$ for $24 \mathrm{~h}$. Sourdoughs were inoculated with $0.5 \%$ of starter culture $\left(10^{10} \mathrm{cfu} / \mathrm{g}\right.$ dough $)$. The fermentations were continued with 3 backsloppings (once every $24 \mathrm{~h}$ ) at $25{ }^{\circ} \mathrm{C}$ using $10 \%$ of the ripe sourdough as the inoculum. After $24 \mathrm{~h}$ of initial fermentation and at the $1^{\text {st }}$ and $3^{\text {rd }}$ refreshment step, samples were taken from the ripe sourdough and analysed. An uninoculated (control) sourdough was prepared under the same conditions. Data were obtained from two independent sourdough fermentations. 


\section{Lactic acid and glucose analysis in sourdough}

All chemicals used in the study were from Sigma-Aldrich. The chemicals were all of analytical grade.

Prior to analyses, dough extracts were treated as described previously (Robert $\boldsymbol{e t}$ al., 2006) with some modifications. Sourdough was homogenized with redistilled water (1:7). Then, the solution was stirred with $2.5 \mathrm{~mL}$ of Carrez I solution and $2.5 \mathrm{~mL}$ of Carrez II solution and was centrifuged for $3 \mathrm{~min}$ at $150 \mathrm{rpm}$. The supernatant was filtered through a $0.45 \mu \mathrm{m}$ filter (Membrane Solutions, USA) prior to analysis.

Glucose and lactic acid were quantified by HPLC apparatus (Gilson, Inc. Meddleton, USA) with an Aminex 87HP column (300 mmx $7.8 \mathrm{~mm}$, Bio-Rad, Mississauge, Canada) at a temperature of $20^{\circ} \mathrm{C}$ and a flow rate of $0.6 \mathrm{~mL} \mathrm{~min}$ with $\mathrm{H}_{2} \mathrm{SO}_{4}(\mathrm{pH}=3.4)$ as the eluent. The quantification was based on a refractive index detector and performed with external standards in duplicate. The results were expressed as mean values. Errors are represented as standard deviations.

\section{Statistical analysis}

Data were compared by Tukey's test. Statistical significance $(\mathrm{p}<0.05)$ was determined with STATISTICA (Statsoft) software.

\section{RESULTS AND DISCUSSION}

The selected autochthonous LAB strains of Lactobacillus coryniformis, Pediococcus pentosaceus and Pediococcus acidilactici applied in this study are facultatively heterofermentative microorganisms that degrade mainly hexoses via the Embden-Meyerhof-Parnas (EMP) pathway and the lactic acid is the major end product (Gänzle et al. 2007). Pediococcus pentosaceus and Pediococcu. acidilactici are important LABs involved as starter cultures in meat, vegetable and dairy fermentation and causing characteristic flavor changes, improving hygienic quality and extending the shelf life of several products (Irmler et al. 2013). Lactobacillus coryniformis has been recently reported to display a variety of potential probiotic properties, to be characterized by a strong antifungal activity and potential to be used as a biopreservative in feed systems (Magnusson, Schnurer, 2001; Sekwati-Monang et al. 2012).

Glucose consumption and lactic acid formation in millet sourdoughs are depicted in Table 1.

Table 1 Glucose utilization and lactic acid formation after $24 \mathrm{~h}, 48 \mathrm{~h}\left(1^{\mathrm{st}}\right.$ refreshment) and $96 \mathrm{~h}$ ( $3^{\text {rd }}$ refreshment) of millet sourdough fermentation. Sourdoughs were inoculated with approximately $10^{10} \mathrm{cfu} / \mathrm{g}$ of each of the six strains, incubated at $25^{\circ} \mathrm{C}$ and back-slopped every $24 \mathrm{~h}$ with $10 \%$ inoculum. Results are shown as means \pm standard deviation of duplicate independent experiments analyzed in duplicate.

\begin{tabular}{|c|c|c|c|}
\hline Strains & $\begin{array}{l}\text { Incubation } \\
\text { time }[\mathbf{h}]\end{array}$ & Glucose utilization $\left[\mathrm{mmol} \mathrm{kg}^{-1}\right]$ & Lactic acid formation $\left[\mathrm{mmol} \mathrm{kg}{ }^{-1}\right]$ \\
\hline L. coryniformis ZFP1 & $\begin{array}{l}24 \mathrm{~h} \\
48 \mathrm{~h} \\
96 \mathrm{~h}\end{array}$ & $\begin{array}{c}8,5 \pm 0,44 \text { a B } \\
46,4 \pm 1,09 \text { b C } \\
\text { n.d. }\end{array}$ & $\begin{array}{l}130,4 \pm 5,41 \text { a F } \\
116,0 \pm 8,13 \text { b D } \\
65,8 \pm 1,33 \text { a AB }\end{array}$ \\
\hline L. coryniformis ZFP4 & $\begin{array}{l}24 \mathrm{~h} \\
48 \mathrm{~h} \\
96 \mathrm{~h}\end{array}$ & $\begin{array}{c}18,4 \pm 0,61 \text { b D } \\
\text { n.d. A } \\
\text { n.d. }\end{array}$ & $\begin{array}{c}99,9 \pm 3,49 \text { b D } \\
87,3 \pm 2,18 \text { a C } \\
65,5 \pm 1,08 \text { a AB }\end{array}$ \\
\hline P. pentosaceus ZFP2 & $\begin{array}{l}24 \mathrm{~h} \\
48 \mathrm{~h} \\
96 \mathrm{~h}\end{array}$ & $\begin{array}{l}\text { n.d. A } \\
63,2 \pm 0,20 \mathrm{D} \\
\text { n.d. }\end{array}$ & $\begin{array}{c}89,0 \pm 2,50 \text { a C } \\
106,0 \pm 2,72 \text { a AB } \\
54,2 \pm 3,37 \text { a BD }\end{array}$ \\
\hline P. pentosaceus ZFP3 & $\begin{array}{l}24 \mathrm{~h} \\
48 \mathrm{~h} \\
96 \mathrm{~h}\end{array}$ & $\begin{array}{c}47,7 \pm 2,90 \text { a G } \\
\text { n.d. A } \\
\text { n.d. }\end{array}$ & $\begin{array}{c}115,4 \pm 5,01 \mathrm{~b} E \\
105,4 \pm 1,08 \mathrm{a} A B \\
70,3 \pm 3,81 \mathrm{~b} A C\end{array}$ \\
\hline P. acidilactici ZFP6 & $\begin{array}{l}24 \mathrm{~h} \\
48 \mathrm{~h} \\
96 \mathrm{~h}\end{array}$ & $\begin{array}{l}14,7 \pm 1,29 \mathrm{C} \\
16,1 \pm 0,21 \mathrm{~B} \\
\text { n.d. }\end{array}$ & $\begin{array}{c}180,9 \pm 5,71 \mathrm{G} \\
113,5 \pm 4,15 \mathrm{BD} \\
77,8 \pm 3,81 \mathrm{AC}\end{array}$ \\
\hline $\begin{array}{l}\text { control } \\
\text { (uninoculated dough) }\end{array}$ & $\begin{array}{l}24 \mathrm{~h} \\
48 \mathrm{~h} \\
96 \mathrm{~h}\end{array}$ & $\begin{array}{c}35,9 \pm 0,80 \mathrm{~F} \\
\text { n.d. A } \\
\text { n.d. }\end{array}$ & $\begin{array}{c}52,8 \pm 1,94 \mathrm{~A} \\
96,7 \pm 2,98 \mathrm{AC} \\
79,7 \pm 7,73 \mathrm{C}\end{array}$ \\
\hline
\end{tabular}

n.d.-not detect
$*$ Means between strains of the same LAB species followed by the different small letters and means between the different LAB species followed by the

different capital letters are significantly different at $\mathrm{p}<0,05$ (Tukey test)

In the studied millet sourdoughs, glucose was the dominant utilized carbohydrate The consumption of glucose, as a major carbon source, was observed in sorghum sourdough (Sekwati-Monang et al. 2012). After the first $24 \mathrm{~h}$ of fermentation, the level of glucose varied depending on the LAB strains used. Moreover, statistically significant differences were observed between strains of the same LAB species (Table 1). In case of $P$. pentosaceus strains ZFP3 and ZFP5, the level of glucose was 47.7 and $26.3 \mathrm{mmol} \mathrm{kg}^{-1}$, respectively, whereas no glucose was detected in sourdough fermented with $P$. pentosaceus ZFP2. Significantly lower amounts of glucose were found in sourdoughs inoculated with $L$. coryniformis ZFP1 and ZFP4 (8.5 and $\left.18.4 \mathrm{mmol} \mathrm{kg}^{-1}\right)$, and P. acidilactici $(14.7$ mmol $\mathrm{kg}^{-1}$ ). Glucose level in the spontaneously fermented millet dough was relatively high $\left(35.9 \mathrm{mmol} \mathrm{kg}^{-1}\right)$, compared to the inoculated samples.

The amount of synthesized lactic acid, after $24 \mathrm{~h}$ of fermentation, ranged between 76.0 and $180.9 \mathrm{mmol} \mathrm{kg}^{-1}$, depending on the strain used. The highest amount was detected in the sourdough fermented with $P$. acidilactici ZFP6 $\left(180.9 \mathrm{mmol} \mathrm{kg}^{-1}\right)$, whereas the lowest was found in sourdough with P. pentosaceus ZFP5 (76.0 mmol $\mathrm{kg}^{-1}$ ).

After $48 \mathrm{~h}$ of incubation ( $1^{\text {st }}$ refreshment), a successive decrease of lactic acid was observed in almost all sourdoughs, except the sample inoculated with $P$. pentosaceus ZFP2 and the non-inoculated one. The differences in the amount of produced lactic acid between the strains of the same LAB species as well as between different LAB species diminished and in few cases became statistically less significant. No significant differences were observed between the sourdoughs fermented with $P$. pentosaceus $\mathrm{ZFP} 2$ and $P$. pentosaceus ZFP3. However, significantly lower amount of lactic acid was synthesized in sourdough fermented with $P$. pentosaceus ZFP5. Compared to the other millet sourdoughs, $L$. coryniformis ZFP1 and $P$. acidilactici ZFP6 exhibited the highest level of lactic acid production.

Considering glucose consumption after $48 \mathrm{~h}$ of incubation, its level varied between the samples and in case of the control and sourdough fermented with $L$. coryniformis ZFP4, P. pentosaceus ZFP3, and P. pentosaceus ZFP5 was not detected. In other samples, its level was higher compared to the samples obtained after $24 \mathrm{~h}$ of incubation.

During $96 \mathrm{~h}$ of sourdough fermentation glucose was completely consumed in all the studied samples. The level of lactic acid ranged from $41.9 \mathrm{mmol} \mathrm{kg}^{-1}$ to 79.7 $\mathrm{mmol} \mathrm{kg}$, and was of about $44 \%$ lower than after the first $24 \mathrm{~h}$ of fermentation. No statistically significant differences were observed between the sample inoculated with strains of the $L$. coryniformis species as well as between the $P$. pentosaceus ZFP2 and P. pentosaceus ZFP5.

Carbohydrate metabolism of LAB and formation of lactic acid during sourdough fermentation is a very complex process. The nature of sourdough microbiota as well as the type of flour used are one of the main factors determining the metabolite kinetics of sourdough fermentation. The metabolic activity of various 
LAB species and their interaction with other sourdough microorganisms are flour specific. The unique chemical composition of wheat, rye and non-wheat flours affect the observed varying behavior of the species participating in the fermentation process. Moreover, the observed differences in the carbohydrate metabolism are not only between the strains of various LAB species but also between the strains of the same LAB species. In our study, statistically significan differences in glucose and lactic acid level between the applied selected LAB starters were detected predominantly after $24 \mathrm{~h}$ of fermentation. During the next fermentation steps, the differences diminished and finally at the end of fermentation were almost comparable. The observed behavior of the applied autochthonous starters results probably from their interaction and competitive activities with other millet sourdough microorganisms.

\section{CONCLUSION}

The present study has shown varied behavior of selected autochthonous LAB starters during millet sourdough fermentation. Among the used starters, $P$. acidilactici ZFP6 exhibited the highest level of lactic acid production in all fermentation steps, compared to the other inoculated sourdoughs. Whereas, the lowest amount of this metabolite was found in sourdoughs fermented with Pediococcus pentosaceus ZFP5.

The obtained results will be a useful tool to better understanding of the carbohydrate metabolism of LAB in the millet sourdough and to the further studies on design of proper LAB starter cultures for millet sourdough preparation.

\section{REFERENCES}

Coda R., Rizzello C.G., Gobbetti M. (2010). Use of sourdough fermentation and pseudo-cereals and leguminous flours for the making of a functional bread enriched of $\gamma$-aminobutyric acid (GABA). International Journal of Food Microbiology, 137, 236-245. http://dx.doi.org/10.1016/j.ijfoodmicro.2009.12.010 Coda R., Di Cagno R., Rizzello C.G., Nionelli L., Edema M.O.,Gobbetti M. (2011). Utilization of African grains for sourdough bread making. Journal of Food Science, 76, M329-M335. http://dx.doi.org/10.1111/j.17503841.2016.02240.x

Coda R., Di Cagno R., Gobbetti M., Rizzello C.G. (2014). Sourdough lactic acid bacteria: Exploration of non-wheat cereal-based fermentation. Food Microbiology, 37: 51-58. http://dx.doi.org/10.1016/j.fm.2013.06.018

Gallagher E., Gormleya T.R., Arendt E.K. (2004). Recent advances in the formulation of gluten-free cereal-based products. Trends in Food Science and Technology, 15: 143-152. http://dx.doi.org/10.1016/j.tifs.2003.09.012

Gänzle M.G., Vermeulen N., Vogel R.F. (2007). Carbohydrate, peptide and lipid metabolism of lactic acid bacteria in sourdough. Food microbiology, 24, 128-138. http://dx.doi.org/10.1016/i.fm.2006.07.006

Irmler S., Bavan T., Oberli A., Roetschi A., Badertscher R., Guggenbühl, Berthoud H. (2013). Catabolism of serine by Pedioccocus acidilactici and Pediococcus pentosaceus. Appl. Environ. Microbiol. 79: 4, 1309-1315. http://dx.doi.org/10.1128/AEM.03085-12

Magnusson J., Schnurer J. (2001). Lactobacillus coryniformis subsp coryniformis strain $\mathrm{Si} 3$ produces a broad-spectrum proteinaceous antifungal compound. Appl. Environ. Microbiol. 67: 1, 1-5. http://dx.doi.org/10.1128/AEM.67.1.1-5.2001

Moroni A.V., Bello F. D., Arendt E.K. (2009). Sourdough in gluten-free bread making: An ancient technology to solve a novel issue? Food Microbiology, 26: 676 - 684. http://dx.doi.org/10.1016/j.fm.2009.07.001

Moroni A.V., Iametti S., Bonomi F., Arendt E.K., Dal Bello F. 2010. Solubility of proteins from non-gluten cereals; a comparative study on combinations of solubilising agents. Food Chemistry, 121, 1225-1230. http://dx.doi.org/10.1016/j.foodchem.2010.02.009

Robert H., Gabriel V., Lefebvre D., Rabier P., Vayssier Y., Fontagne-Faucher C. 2006. Study of the behavior of Lactobacillus plantarum and Leuconoctoc starters during a complete wheat sourdough breadmaking process. LWT, 39, $256-265$. http://dx.doi.org/10.1016/j.lwt.2005.01.013

Sterr Y., Weiss A., Schmidt H. 2009. Evaluation of lactic acid bacteria for sourdough fermentation of amaranth. International Journal of Food Microbiology, 136, 75-82. http://dx.doi.org/10.1016/j.ijfoodmicro.2009.09.006 Verma V., Patel S. (2013). Value added products from nutri-cereals: Finger millet (Eleusine coracana). Emir. J. Food Agric. 3: 169-176.

http://dx.doi.org/10.9755/ejfa.v25i3.10764 